\title{
Bronchopulmonary dysplasia: incidence and severity in a cohort of premature infants born at high altitude.
}

\author{
Jefferson Buendia ${ }^{1}$, Cristian Ramieez ${ }^{2}$, and Dione Benjumea ${ }^{2}$ \\ ${ }^{1}$ University of Antioquia \\ ${ }^{2}$ UNIREMINGTON Facultad de Ciencias de la Salud
}

June 2, 2021

\begin{abstract}
Background: Bronchopulmonary dysplasia (BPD) is the most common cause of chronic lung disease in children born prematurely. There is little information about the epidemiology and severity of BPD places with high altitude. This study aimed to evaluate the frequency of BPD severity levels and the associated risk factors with severity in a cohort of preterm newborns [?]34 weeks of gestational age born in Rionegro, Colombia Materials and methods: We carried out a retrospective analytical cohort of preterm newborns without major malformations from Rionegro, Colombia between 2011-2018 admitted to neonatal intensive unit at high altitude (2200m above sea level). The main outcomes were the incidence and severity of bronchopulmonary dysplasia. Results: The bronchopulmonary dysplasia incidence was $25.7 \%$ (95\% CI, 21.6-29.9). Bronchopulmonary dysplasia was moderate in $62.1 \%$ of patients and severe in $26.7 \%$. The most frequent complications were sepsis $(62.1 \%)$, hyaline membrane disease $(59.5 \%)$, and pneumonia (26.7\%). After modeling regression analysis, and force in the model the variable gestational age at birth, the final variables associated with BPD severity levels were: duration of oxygen therapy and pulmonary hypertension. Conclusion: The incidence of BPD was higher and similar to cities with higher altitudes. In our population, the variables associated with BPD severity levels were: duration of oxygen therapy and pulmonary hypertension. It is necessary to increase the awareness of risk factors, the effect of clinical practices, and early recognition of bronchopulmonary dysplasia to reduce morbidity in patients with this pathology.
\end{abstract}

\section{Hosted file}

main text with title page 290521.docx available at https://authorea.com/users/316889/ articles/524640-bronchopulmonary-dysplasia-incidence-and-severity-in-a-cohort-ofpremature-infants-born-at-high-altitude

\section{Hosted file}

Table 1.docx available at https://authorea.com/users/316889/articles/524640-bronchopulmonarydysplasia-incidence-and-severity-in-a-cohort-of-premature-infants-born-at-high-altitude

\section{Hosted file}

Table 2.docx available at https://authorea.com/users/316889/articles/524640-bronchopulmonarydysplasia-incidence-and-severity-in-a-cohort-of-premature-infants-born-at-high-altitude 


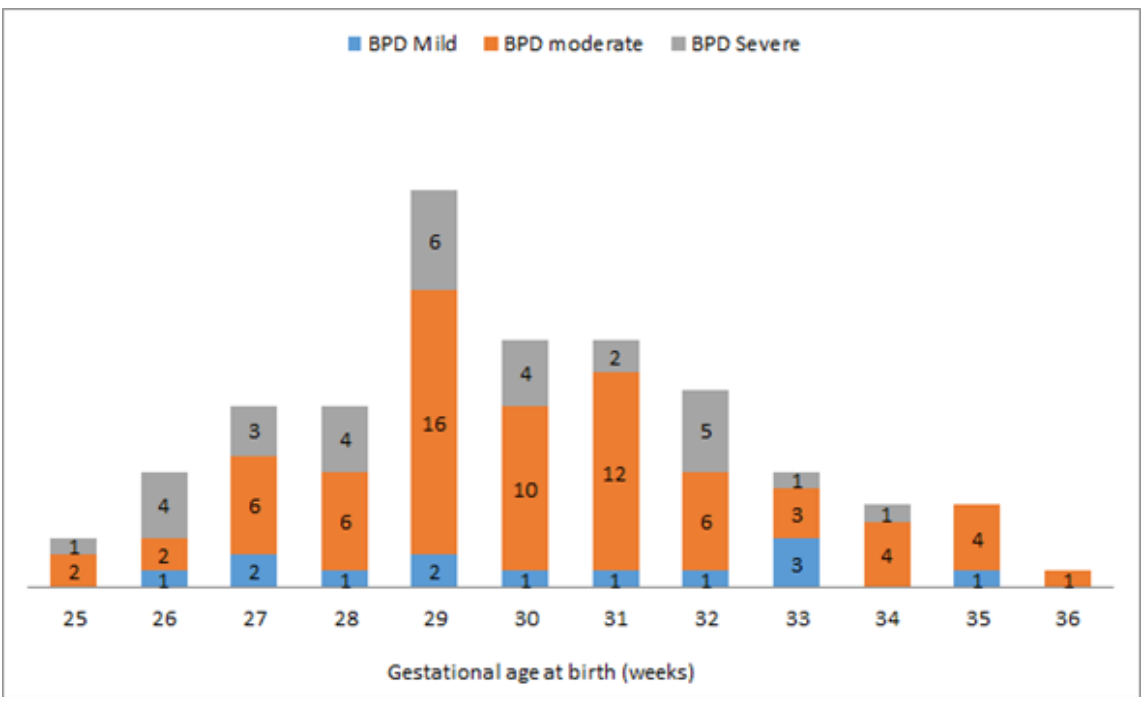

